\title{
Is cochlear implantation a good treatment method for profoundly deafened elderly?
}

This article was published in the following Dove Press journal:

Clinical Interventions in Aging

I October 2013

Number of times this article has been viewed

\section{Magdalena Lachowska \\ Agnieszka Pastuszka \\ Paulina Glinka \\ Kazimierz Niemczyk}

Department of Otolaryngology, Hearing Implant Center, Medical University of Warsaw, Warsaw, Poland
Purpose: To assess the benefits of cochlear implantation in the elderly.

Patients and methods: A retrospective analysis of 31 postlingually deafened elderly ( $\geq 60$ years of age) with unilateral cochlear implants was conducted. Audiological testing included preoperative and postoperative pure-tone audiometry and a monosyllabic word recognition test presented from recorded material in free field. Speech perception tests included Ling's six sound test (sound detection, discrimination, and identification), syllable discrimination, and monosyllabic and multisyllabic word recognition (open set) without lip-reading. Everyday life benefits from cochlear implantation were also evaluated.

Results: The mean age at the time of cochlear implantation was 72.4 years old. The mean postimplantation follow-up time was 2.34 years. All patients significantly improved their audiological and speech understanding performances. The preoperative mean pure-tone average threshold for $500 \mathrm{~Hz}, 1,000 \mathrm{~Hz}, 2,000 \mathrm{~Hz}$, and 4,000 Hz was $110.17 \mathrm{~dB}$ HL. Before cochlear implantation, all patients scored $0 \%$ on the monosyllabic word recognition test in free field at $70 \mathrm{~dB}$ SPL intensity level. The postoperative pure-tone average was $37.14 \mathrm{~dB}$ HL (the best mean threshold was $17.50 \mathrm{~dB} \mathrm{HL}$, the worst was $58.75 \mathrm{~dB} \mathrm{HL}$ ). After the surgery, mean monosyllabic word recognition reached $47.25 \%$. Speech perception tests showed statistically significant improvement in speech recognition.

Conclusion: The results of this study showed that cochlear implantation is indeed a successful treatment for improving speech recognition and offers a great help in everyday life to deafened elderly patients. Therefore, they can be good candidates for cochlear implantation and their age alone should not be a relevant or excluding factor when choosing candidates for cochlear implantation.

Keywords: cochlear implantation, elderly, audiometry, speech perception, speech recognition, hearing loss, hearing aid

\section{Introduction}

Most of the hearing-impaired elderly have difficulties with speech perception that negatively affects their social life. In this group of patients, hearing loss is one of the most frequent difficulties. Some of them suffer from severe-to-profound hearing loss (hearing thresholds $\geq 70 \mathrm{~dB}$ HL) and appropriately fitted conventional hearing aids provide very limited benefit, which may lead to social isolation, loneliness, and depression, that may seriously affect their everyday life. They become dependent on others in daily activities, such as going out, going for doctors' appointments, watching television, or answering the phone. In such cases, cochlear implantation (CI) might be a method of choice for the treatment of hearing loss. Its benefits in the pediatric and adult population have been well documented. Recently, there has been a growing interest in CI in
Correspondence: Magdalena Lachowska Department of Otolaryngology, Hearing Implant Center, Medical University of Warsaw, Banacha Street, Warszawa (Warsaw) 02-097, Poland

Tel +48225992521

Fax +48225992523

Emailmlachowska@wum.edu.pl 
deafened elderly. Previously, the use of cochlear implants in this group of recipients was very limited as compared to younger patients, possibly due to the assumption that elderly people might not perform well enough. The reasons might have been as follows: 1) risks of CI surgery that may outweigh the benefits; 2) older patients with cochlear implants might have limited improvement in auditory abilities because of central deficits in the integration centers of hearing and/or auditory pathways; 3 ) coexisting physical and cognitive capabilities might also have an impact on perioperative and postoperative recovery and rehabilitation. ${ }^{1-3}$ Recent experience with implanted elderly, including ours, is in opposition to those previously misleading assumptions and supports the idea of CI in this group of patients.

The aim of this retrospective study was to analyze the benefits of CI in elderly patients ( $\geq 60$ years old) based on audiological and speech perception assessments along with evaluation of CI influence on daily activities.

\section{Materials and methods}

This retrospective study analyzes data from 31 patients with postlingual bilateral profound hearing loss. All of them were implanted unilaterally with a multichannel cochlear implant, and received the following implants: 17 Cochlear ${ }^{\circledR}$ Nucleus (nine Nucleus Freedom, eight Cochlear CI512; Cochlear, Macquarie Park, Australia), 12 Digisonic $^{\circledR}$ SP (Neurelec, Vallauris, France), and two Harmony ${ }^{\mathrm{TM}}$ (Advanced Bionics, Valencia, CA, USA). Before the surgery, all patients underwent very careful multidisciplinary evaluation to determine their candidacy for $\mathrm{CI}$. The inclusion criteria were as follows: severe-to-profound bilateral sensorineural hearing loss; postlingual onset of hearing impairment, limited to no benefit from appropriately fitted hearing aids (monosyllabic word recognition score in free field $\leq 35 \%$ at $70 \mathrm{~dB}$ SPL in aided condition, rely heavily on lip-reading); social isolation due to deafness; no medical or radiological contraindications for surgery; desire to improve hearing; good motivation; and realistic expectations from CI. A preoperative general medical assessment was performed to exclude underlying disease, which would be a contraindication for surgery under general anesthesia. Temporal bone computer tomography scans were obtained to assist in surgical planning.

The mean age at the time of implantation was 72.4 years old (standard deviation $[\mathrm{SD}]=8.1$; range from 60 to 87 years old). The speech processors were activated 1 month after the surgery in all cases, followed by mapping of the device. Almost all patients continued to use their cochlear implant at least 8 hours a day. One patient decided not to use her implant anymore due to no benefit from it. She stopped using her implant about 1.5 years after implantation.

All patients returned for regular follow-up and fitting sessions. The majority of them underwent aural rehabilitation. A few patients did not go for rehabilitation appointments due to difficulty in reaching the rehabilitation center. They lived far away and according to their statements, it was too complicated for them to go to rehabilitation appointments. The patient who stopped using her CI was one of them.

The mean post-implantation follow-up time was 2.34 years, the shortest follow-up time was 4 months (two patients), all others (29 patients) were followed-up $\geq 6$ months, and 18 for more than 12 months. The longest follow-up time was 9.61 years. The study analyzes data at time intervals of 3, 6, and 12 months post-implantation.

Preoperative and postoperative audiometric evaluation included pure-tone audiometry in free field (from $125 \mathrm{~Hz}$ to $8,000 \mathrm{~Hz}$ ) and word recognition in free field measured using the Polish phonetically balanced monosyllabic word test from recorded material in quiet conditions. The phonetically balanced monosyllabic word test consists of ten lists of 20 monosyllabic words. Each list is a formally used selection of words with phonemes that appear with the same frequency at which they occur in the normal lexicon (at which they occur in ordinary conversation in that language, Polish in our case). The word recognition test in free field was measured at different presentation levels to obtain word recognition scores (percentage of correct recognition) at a range of stimulus levels, from minimum $(0 \%)$ to maximum possible score. The score at $70 \mathrm{~dB}$ SPL (normal speech level) was then compared. The minimum score (speech detection threshold) was the lowest sound intensity at which speech was detectable in $50 \%$, but was not recognized yet (recognition $0 \%$ ); in other words, the patient was only aware of the sound (words) in $50 \%$ of presented sounds (words).

The speech perception tests were performed by a speech therapist and included the following: Ling's six sound test (sound detection, discrimination, and identification), syllable discrimination, and monosyllabic and multisyllabic word recognition (open set) without lip-reading. Those tests were conducted using live voice at the presentation level of about 65-70 dB SPL. Ling's six sound test was applied to test the three following skill levels: sound detection, discrimination, and identification, with identification being the most difficult task in this test. First, detection was checked, then discrimination as the second level skill in the hierarchy. In order to identify Ling's sounds, the individual was required to indicate the sound he/she heard by saying it (repeating the sound). In 
the results, we show the identification score of Ling's test. In the monosyllabic and multisyllabic word recognition tests, the lists of 20 words were used to examine discrimination and identification of skills. The scores show the percentage of proper identification of the words used in the tests.

In the follow-up appointments, along with auditory evaluation, speech perception tests, and speech processor fitting, the patients were asked about their everyday activities and the influence of the implantation on their lives. The questions evaluated following issues: 1) auditory-verbal communication along with perception of spoken language through the auditory sensory modality; improvements in communication with a familiar and unfamiliar person, necessity of lip-reading, and ability to talk through the phone using a cochlear implant; 2) interactions with household members, relatives, and friends; 3 ) the openness to meet new people and to engage in new interactions; 4) independence in everyday activities like going out, shopping, or doctor's appointments; 5) speech perception in noisy environments. The responses to those questions were very helpful in evaluating the everyday benefits of CI in those patients.

In the follow-up appointments, auditory evaluation and speech perception tests assisted in the speech processor's fitting procedure (mapping). The mapping was always conducted very carefully in order to obtain the best possible performance.

STATISTICA software version 10 (StatSoft, Inc., Tulsa, OK, USA) was used for statistical analysis of data. Data were tested for normality, parametric, and nonparametric criteria. Student's $t$-test, repeated measures analysis of variance, and correlation analysis were used and $P$-values of $<0.05$ were considered statistically significant.

\section{Results}

All patients significantly improved their audiological and speech perception performances. The audiological results described below present free field performance.

The preoperative free field mean pure-tone threshold for $500,1,000,2,000$, and 4,000 Hz (pure-tone average [PTA]) was $110.17 \mathrm{~dB}$ HL ( $\mathrm{SD}=16.84$, the best mean threshold was $78.75 \mathrm{~dB} \mathrm{HL}$, and the worst still detectable threshold was $130 \mathrm{~dB}$ HL). Before CI, all patients scored $0 \%$ on monosyllabic word recognition in free field at $70 \mathrm{~dB}$ SPL intensity level. None of them were able to have telephone conversations. The postoperative mean PTA was $37.14 \mathrm{~dB}$ HL ( $\mathrm{SD}=9.89$, the best mean threshold was $17.50 \mathrm{~dB}$ HL, and the worst mean threshold was $58.75 \mathrm{~dB}$ HL). After the surgery, mean monosyllabic word recognition reached $47.25 \%$. Figure 1 presents mean free field audiometric results.

Pure-tone audiometry results for frequencies of 500, 1,000, 2,000, and 4,000 Hz before and after CI were compared (changes over time). Statistical analysis showed that there was a strong significant improvement in thresholds for all mentioned frequencies $(P<0.01)$. A similar outcome was achieved in the audiometric test of monosyllabic word recognition from recorded material in free field at the intensity of $70 \mathrm{~dB}$ SPL, from $0 \%$ of word recognition before CI to $47.25 \%$ after implantation (Figure 1 ).

Speech perception tests performed by speech therapists before and after CI also presented highly statistically significant improvement $(P<0.01)$ over time. Before implantation, only eight patients were able to identify some of Ling's sounds, only two were able also recognize some of the syllables, and only five were able to recognize a few multisyllabic words in the open set test. All of the others scored $0 \%$ in speech perception tests before surgery. After CI, this situation changed and evolved over time. After 6 months of implant use the mean score in Ling's six sound test reached $91.43 \%$, the syllable discrimination score reached $33.93 \%$, the monosyllabic words score reached $34.29 \%$, and the multisyllabic words recognition score reached 59.64\%. After 12 months, the scores in all speech perception tests increased, reaching the mean of $98.33 \%, 42.22 \%, 46.11 \%$, and $75.56 \%$, respectively (Figure 2 ).

In the analyzed patients, three groups could be distinguished using following criteria: 1) a low benefits group - no auditory-verbal communication, only detection of sounds, implant aided free field PTA $\geq 50 \mathrm{~dB} \mathrm{HL}$; 2) good benefits group - auditory-verbal communication with familiar persons with a little help of lip-reading, implant aided free field PTA $<50 \mathrm{~dB}$ HL and $\geq 30 \mathrm{~dB} \mathrm{HL}$; and 3 ) a very good benefits group - auditory-verbal communication with familiar and unfamiliar individuals even without lip-reading, implant aided free field PTA less than $30 \mathrm{~dB}$ HL.

The low benefits group of patients presented no auditory-verbal communication and was the minority (five patients, $16.13 \%$, three of them were under 70 years old). In those cases, the cochlear implant provided sense of sounds, but did not improve communication skills. Their social life remained reduced to minimum interactions. Their mean PTA was $53.25 \mathrm{~dB}$ HL (SD $=3.59$ ), with only $12 \%$ monosyllabic word recognition in the free field test at $70 \mathrm{~dB}$ SPL intensity level.

In the good benefits group of patients (19 patients, $61.29 \%$ ), the cochlear implant enabled them to hear sounds 
$\mathrm{HZ}$

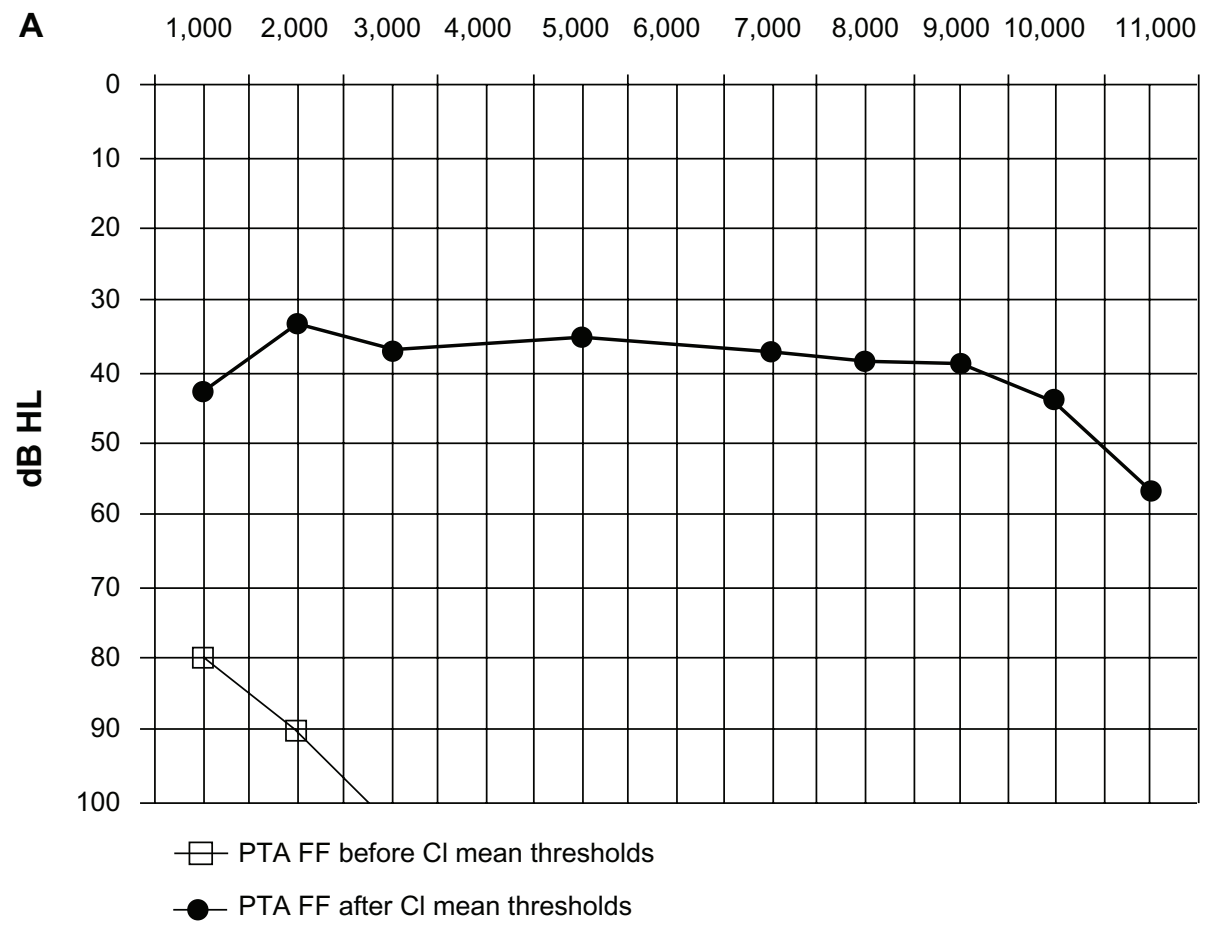

B

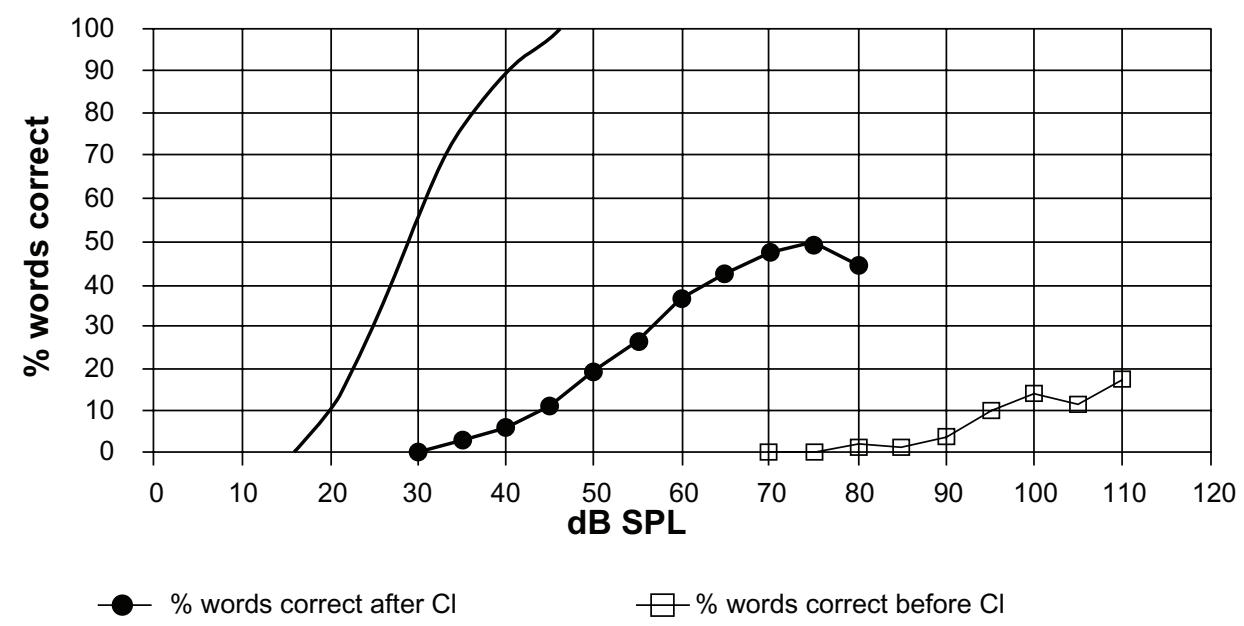

Figure I Results of free field audiometric tests in elderly patients before and after cochlear implantation.

Notes: In panel (A) pure-tone audiogram thresholds are shown. In panel (B) speech recognition test scores measured using the Polish phonetically balanced monosyllabic word test in quiet from recorded material are presented. In panel (B) the plain curve represents normal hearing results as a reference. The plain curve in panel (B) represents normal hearing results as a reference.

Abbreviations: $\mathrm{Cl}$, cochlear implantation; FF, free field; PTA, pure-tone average.

and provided better communication and better contact with household members, relatives, and friends, and in most cases with unfamiliar individuals with little help from lip-reading. This led to increased independence in everyday life. The mean PTA was $37.04 \mathrm{~dB}$ HL ( $\mathrm{SD}=5.56$ ), with $52.73 \%$ mean monosyllabic word recognition.

In the very good benefits group, seven patients $(22.58 \%)$ demonstrated very good perception of spoken language through the auditory-sensory modality. In their case, the cochlear implant provided them with great help in communication. It offered them a possibility to have conversation not only with family and friends, but also with an unfamiliar person even without lip-reading, and in most cases, with several unfamiliar people. A few of them were able to have simple conversations with a little help from lip-reading in noisy environments. Most of those patients were able to have conversations on the phone. Their mean monosyllabic word recognition in free field reached $76 \%$ 


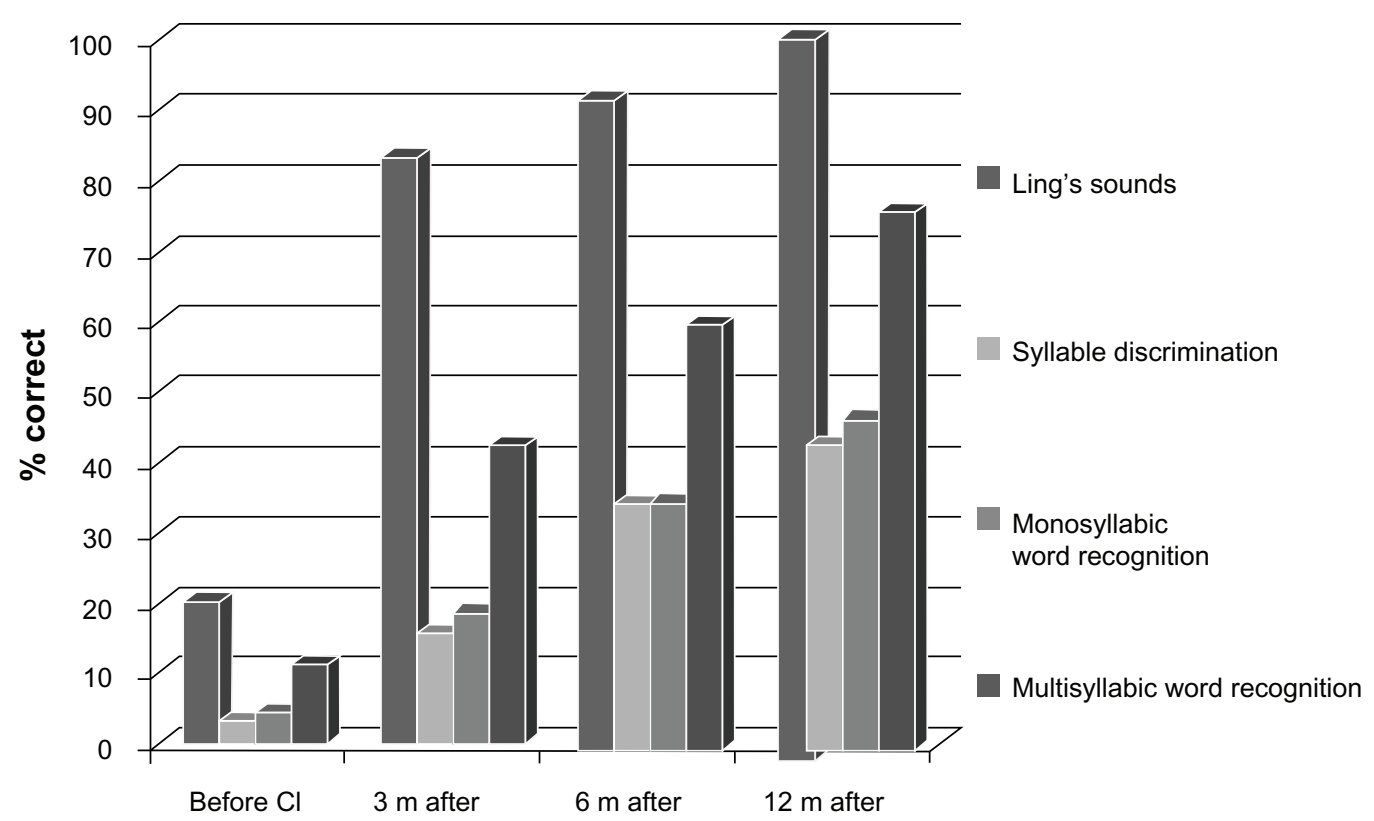

Figure 2 Speech perception tests results of Ling's six sound test, syllable discrimination, monosyllabic and multisyllabic word recognition tests without lip-reading before cochlear implantation, and 3, 6, and 12 months after implantation.

Note: In each test, the improvement over time is easily noted.

Abbreviations: $\mathrm{Cl}$, cochlear implantation; $\mathrm{m}$, months.

( $\mathrm{SD}=14.31$ ), and mean implant aided PTA in free field was $25.89 \mathrm{~dB}$ HL ( $\mathrm{SD}=3.76)$. They often met with other people, neighbors and friends, and were open to meet new people. In that group, only one patient was under 70 years old, all others were over 73 and the oldest was 87 years old.

The results of the postoperative free field pure-tone audiogram and monosyllabic word recognition test from recorded material in all three groups of patients are presented in Figure 3.

The correlation analysis showed that age was not correlated with the postoperative performance in this group of elderly patients $(P>0.05)$.

There were no perisurgical complications and no major postsurgical complications. Four patients reported vertigo. In one case, the vertigo was present before the surgery but remained at the same level afterwards. It did not matter if the implant was turned on or off, in both situations it did not influence the vertigo feeling. The patient was scheduled for postural rehabilitation. In this case, hearing benefits after implantation were very good. This patient was able to talk on a phone using her cochlear prosthesis. In the three other cases, vertigo appeared some time after the surgery, but diminished over the time of rehabilitation.

\section{Discussion}

Conventional hearing aids effectively treat different degrees of hearing loss, except for cases of severe-to-profound hearing impairment, in which even the most powerful hearing aids may not be enough to solve the auditory needs of these patients. Such hearing loss in the elderly leads to isolation from society and contributes to depression..$^{4-9}$ In those cases, CI appears to be the optimal solution. For individuals with severe-to-profound hearing impairments, CI is a widely accepted and effective treatment method providing access to sound. However, implantation in the elderly still remains a point of discussion. Some factors that are specific for the elderly population may affect the outcomes of this high technology device; ie, long duration of deafness, age-related degenerative changes in the auditory pathways, progressive central auditory dysfunction, diminished intellectual and cognitive abilities, and coexisting morbidities which could increase the perioperative complications. ${ }^{1,2,10}$ A review of the literature provided evidence of improved hearing and speech perception ability in elderly cochlear implant recipients. ${ }^{9-15}$

Our study demonstrated that age should not be a factor in deciding who should undergo CI. Most of our elderly patients with cochlear implants presented good and very good results, and according to their statements, they cannot imagine a life without the device. Adaptation to hearing with the cochlear implant took them a relatively short time. Most of the patients started to notice a difference after about 2-3 months with progress over time. Their audiological outcomes and speech perception improved dramatically over time. Our findings are in agreement with those in the 
A

$\mathrm{Hz}$

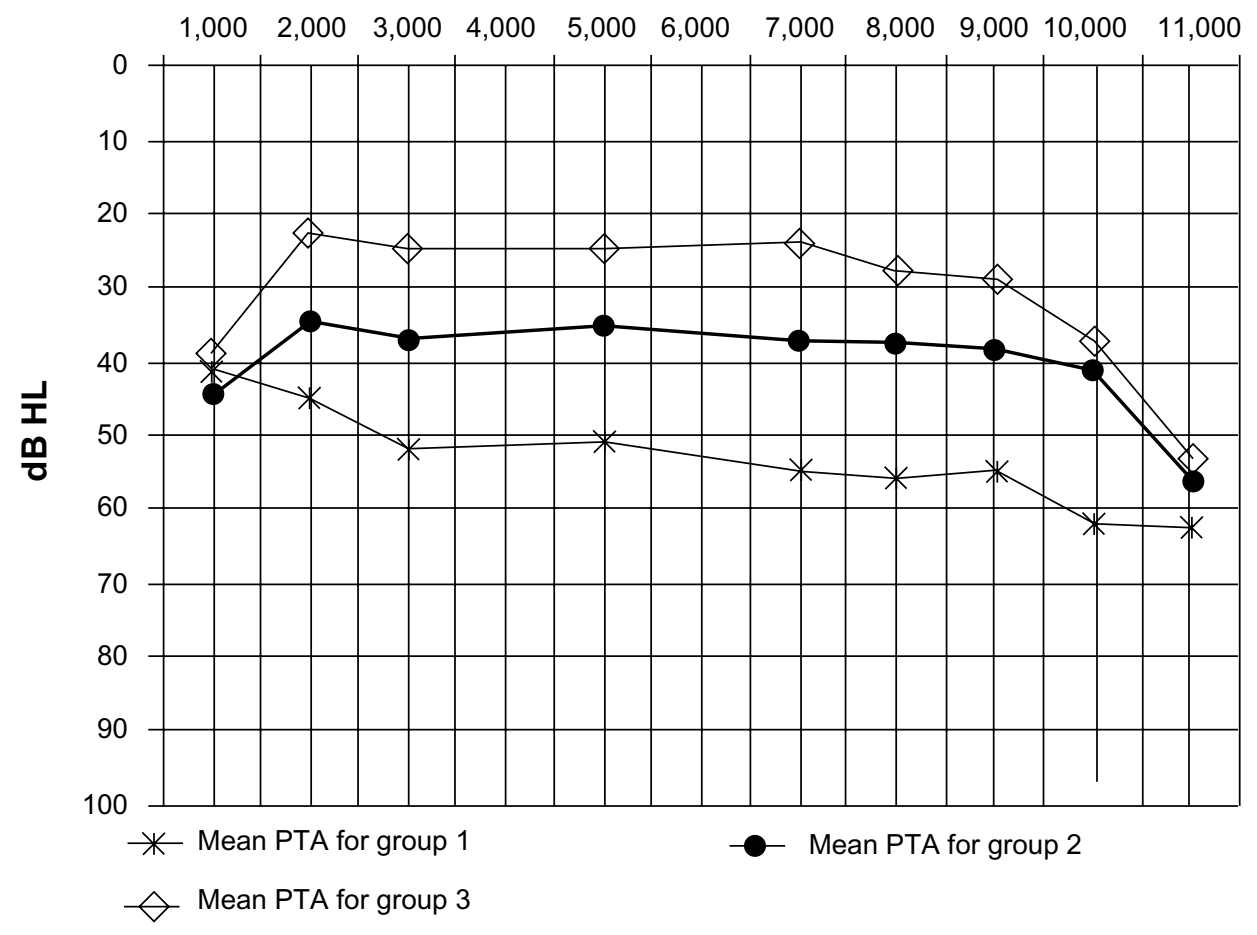

B

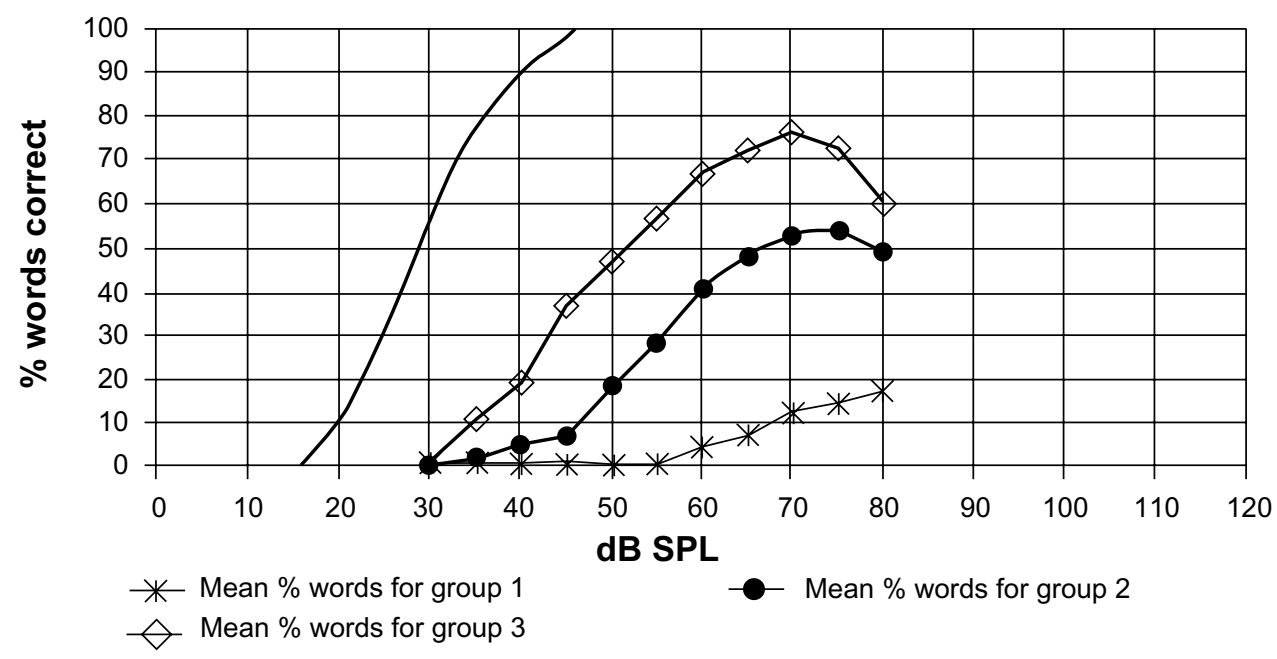

Figure 3 Results of free field audiometric tests in elderly patients before and after cochlear implantation with regard to the three groups of patients.

Notes: The patients were grouped according to implantation benefits as follows. Group I: almost no benefits. Group 2: good benefits. Group 3: very good benefits. In panel (A) pure-tone audiogram mean thresholds are shown. In panel (B) speech perception test scores measured using the Polish phonetically balanced monosyllabic word test in quiet from recorded are presented. The plain curve in panel (B) represents normal hearing results as a reference.

Abbreviation: PTA, pure-tone average.

existing literature. In their study, Labadie et $\mathrm{al}^{16}$ showed that the elderly population achieved significant improvement in auditory performance after CI. The authors stated that the elderly might need more time to reach the same scores as their younger counterparts.

Similar to the results of our patients are the ones reported by Shin et al. ${ }^{17}$ Most subjects in their study reported the ability to be aware of the environmental sounds, and to have a conversation with a person who is familiar or unfamiliar to them. However, in contrast to their report, some of the patients from our study reported an improvement also in conversation in noisy environments with a little help from lip-reading and some of them were able to answer the phone. Vermeire et $\mathrm{al}^{18}$ showed once more that audiological 
performance of the geriatric population after CI led to useful hearing and the results showed a significant improvement in quality of life.

Kelsall et $\mathrm{al}^{14}$ and Waltzman et $\mathrm{al}^{19}$ demonstrated in their studies that elderly patients with severe-to-profound hearing impairment obtained benefits from CI despite the possible existence of age-related auditory processing problems. Sterkers et $\mathrm{al}^{20}$ also reported similar observations in a geriatric population with cochlear implants. Results of our study strongly support those findings. Our study showed that age was not correlated with the postoperative performance and therefore should not be a predictive factor of patients' postoperative success.

When it comes to surgical complications of CI in our study, we did not register any perioperative or major postoperative problems. However, we registered four minor complications and all of them were vertigo; one was present before the surgery and remained after, and three others appeared after the surgery but diminished with time of rehabilitation. It should be kept in mind that problems that are more serious may happen in the implanted elderly; ie, Kelsall et a ${ }^{14}$ reported two cases of major complications that required revision surgery. Migirov et $\mathrm{al}^{10}$ reported the following major complications: implant reaction in one patient, one case of facial nerve paralysis, and one cholesteatoma. They also reported some minor complications: three incidents of seroma, two wound infections, and five vertigo cases. Transient impairment of the vestibular system that caused vertigo resolved spontaneously within the first postoperative month. In their recent retrospective review about CI in the elderly (aged $\geq 60$ years old), Chen et $\mathrm{al}^{21}$ reported minor complications in $9.2 \%$ of patients (surgical site infection, balance problems, delayed postoperative facial weakness, and facial nerve stimulation) and major complications in 4.7\% (meningitis, immediate postoperative facial weakness, device failure, flap dehiscence, and necessity of surgical removal). Surgical removal was required in $3.8 \%$ of the analyzed patients. The authors stated that safety concerns for CI in the elderly were comparable to those of younger adults and children. In opposition to the mentioned studies, Shin et $\mathrm{al}^{17}$ reported no major complications.

In their literature review about CI in a geriatric population, Yeagle et $\mathrm{al}^{22}$ stated that the risks associated with CI surgery did not significantly increase with age. Labadie et $\mathrm{al}^{16}$ presented no significant difference in operative time, length of stay in the hospital, hospital charges, and audiological speech recognition scores between younger and older implanted patients. We agree with their opinion that as with any other surgical procedure, the risks and benefits of CI need to be discussed in detail with the patients and their family members prior to surgery. However, not only surgical risks should be discussed. We support the idea that patient counseling should also be focused on establishing appropriate expectations as they relate to outcomes, including limitations of the cochlear implant and its maximum benefits. For that reason, we divided our patients into three groups based on postoperative performance. In our opinion, it made a good point about differences in patient results. This should be discussed with patients and their families prior to surgery.

It is important to counsel not only patients themselves, but also to involve their family in the whole process. Most elderly patients are usually no longer drivers themselves and some of them live far away, often lacking their own transportation to appointments. Distance and transportation issues may further impede or limit access to appropriate care, as occurred in a few cases in our study. Additionally, coexisting disabilities including poor vision and diminished manual abilities and cognition can further affect the ability to use the cochlear implant successfully. Those are some of the reasons why family members are important to be involved in counseling and should become an integral part of cochlear implant rehabilitation. That is how we do it in our department.

As shown in our study, cochlear implants in deafened elderly are of great help in communication with other people. The cochlear implant enabled them to hear sounds and provided better contact with household members, relatives, and friends. In most cases, it offered the possibility of conversation with unfamiliar individuals with a little help from lip-reading. In some cases, it allowed conversation with unfamiliar individuals without lip-reading and for phone conversations. As mentioned before, without an implant, the deafened elderly would have been dependent on their family members in everyday life. The CI offered the majority of them a chance for one-on-one conversations, which offered more independence from family members. The doctor's appointments may serve as an example. In case of any disease, the elderly with the implant were able to be more involved in the conversation or even talk one-on-one with a doctor and in that way to be much more independent in making decisions regarding their health and life. Moreover, it is important that family and general physicians learn more about cochlear implants in the elderly. Following Chen et al's ${ }^{21}$ opinion, CI in deafened elderly is still quite low. More studies on the subject, including differences in results of CI in deafened elderly, such as the results presented in our study, would contribute to help family and general physicians in 
more informative counseling. The elderly come to these doctors most often when they seek help for health problems, including hearing.

We are in agreement with Chen et al's ${ }^{21}$ opinion that future research and publications are needed for better understanding of differences in the benefits of $\mathrm{CI}$ in older patients.

\section{Conclusion}

The results of this study showed encouraging outcomes, that $\mathrm{CI}$ in the severe-to-profoundly deafened adult population over 60 years old provided improvement in auditory performance, speech perception skills, and communication ability, which led to increased independence. Our study provides more evidence that CI is indeed a successful treatment for improving speech perception in deafened elderly and offers them a chance to become more active in everyday life. The elderly can be good candidates for CI and they should not be denied it based on age alone. However, careful consideration must be given to various multidisciplinary challenges that exist within this population. Eventual neural degeneration aspects and inefficient central auditory processing in the elderly should be taken into account in the preoperative assessment. This group of patients is not homogenous and as presented in our study, the postoperative implantation results may vary among them. Proper counseling is crucial when evaluating elderly candidates for cochlear implant. Our study stresses that fact and may be helpful for clinicians in making CI recommendations for their patients. Still, as shown in our results, it is clear that age should not be a relevant or excluding factor when choosing candidates for cochlear implant surgery.

\section{Disclosure}

The authors report no conflicts of interest in this work.

\section{References}

1. Welsh LW, Welsh JJ, Healy MP. Central presbycusis. Laryngoscope. 1985;95(2):128-136.

2. Schuknecht HF, Gacek MR. Cochlear pathology in presbycusis. Ann Otol Rhinol Laryngol. 1993;102(1 Pt 2):1-16.

3. Buchman CA, Fucci MJ, Luxford WM. Cochlear implants in the geriatric population: benefits outweigh risk. Ear Nose Throat J. 1999; 78(7):489-494.
4. Mulrow CD, Aquilar C, Endicott JE, et al. Association between hearing impairment and the quality of life in elderly individuals. J Am Geriatr Soc. 1990;38(1):45-50.

5. Scherer MJ, Frisina DR. Characteristic associated with marginal hearing loss and subjective well-being among a sample of older adults. J Rehabil Res Dev. 1998;35(4):420-426.

6. Hallam R, Ashton P, Sherbourne K, Gailey L. Acquired profound hearing loss: mental health and other characteristic of large sample. Int J Audiol. 2006;45(12):715-723.

7. Knutson JF, Johnson A, Murray KT. Social and emotional characteristics of adults seeking a cochlear implants and their spouses. Br J Health Psychol. 2006;11(Pt 2):279-292.

8. Dalton DS, Cruickshanks KJ, Klein BE, Klein R, Wiley TL, Nondahl DM. The impact of hearing loss on quality of life in older adults. Gerontologist. 2003;43(5):661-668.

9. Poissant SF, Beaudoin F, Huang J, Brodsky J, Lee DJ. Impact of cochlear implantation on speech understanding, depression, and loneliness in the elderly. J Otolaryngol Head Neck Surg. 2008;37(4):488-494.

10. Migirov L, Taitelbaum-Swead R, Drendel M, Hildesheimer M, Kronenberg J. Cochlear implantation in elderly patients: surgical and audiological outcome. Gerontology. 2010;56(2):123-128.

11. Chatelin V, Kim EJ, Driscoll C, et al. Cochlear implant outcomes in the elderly. Otol Neurotol. 2004;25(3):298-301.

12. Eshraghi AA, Rodriguez M, Balkany TJ, et al. Cochlear implant surgery in patients more than seventy-nine years old. Laryngoscope. 2009;119(6):1180-1183.

13. Francis HW, Chee N, Yeagle J, Cheng A, Niparko JK. Impact of cochlear implants on the functional health status of older adults. Laryngoscope. 2002;112(8 Pt 1):1482-1488.

14. Kelsall DC, Shallop JK, Burnelli T. Cochlear implantation in the elderly. Am J Otol. 1995;16(5):609-615.

15. Leung J, Wang NY, Yeagle JD, et al. Predictive models for cochlear implantation elderly candidates. Arch Otolaryngol Head Neck Surg. 2005;131(12):1049-1054.

16. Labadie RF, Carrasco VN, Gilmer CH, Pillsbury HC. Cochlear implant performance in senior citizens. Otolaryngol Head Neck Surg. 2000;123(4):419-424.

17. Shin YJ, Fraysse B, Deguine O, et al. Benefits of cochlear implantation in elderly patients. Otolaryngol Head Neck Surg. 2000;122(4):602-606.

18. Vermeire K, Brokx JP, Wuyts FL, Cochet E, Hofkens A, Van de Heyning PH. Quality-of-life benefit from cochlear implantation in the elderly. Otol Neurotol. 2005;26(2):188-195.

19. Waltzman SB, Cohen NL, Shapiro WH. The benefits of cochlear implantation in the geriatric population. Otolaryngol Head Neck Surg. 1993;108(4):329-333.

20. Sterkers O, Mosnier I, Ambert-Dahan E, Herelle-Dupuy E, BozorgGrayeli A, Bouccara D. Cochlear implants in elderly people: preliminary results. Acta Otolaryngol Suppl. 2004;(552):64-67.

21. Chen DS, Clarrett DM, Li L, Bowditch SP, Niparko JK, Lin FR. Cochlear implantation in older adults: long-term analysis of complications and device survival in a consecutive series. Otol Neurotol. 2013;34(7): 1272-1277.

22. Yeagle JD, Ceh KM, Francis HW. Geriatric cochlear implantation. Operative Techniques in Otolaryngology-Head and Neck Surgery. 2010;21(4):266-271.
Clinical Interventions in Aging

\section{Publish your work in this journal}

Clinical Interventions in Aging is an international, peer-reviewed journal focusing on evidence-based reports on the value or lack thereof of treatments intended to prevent or delay the onset of maladaptive correlates of aging in human beings. This journal is indexed on PubMed Central, MedLine, the American Chemical Society's 'Chemical Abstracts
Dovepress

Service' (CAS), Scopus and the Elsevier Bibliographic databases. The manuscript management system is completely online and includes a very quick and fair peer-review system, which is all easy to use. Visit $\mathrm{http}: / /$ www.dovepress.com/testimonials.php to read real quotes from published authors. 